\title{
Synthesis of (3S)-Hydroxyandrosta-5,7-diene-17-ones via Intramolecular Cobalt-Mediated [2+2+2] Cycloaddition ${ }^{1}$
}

\author{
Ulrich Groth,* Norbert Richter, Aris Kalogerakis \\ Fachbereich Chemie der Universität Konstanz, Universitäts Str. 10, Postfach M-720, 78457 Konstanz, Germany \\ Fax +49(7531)884155; E-mail: ulrich.groth@ uni-konstanz.de
}

\begin{abstract}
A new method for the synthesis of lumisterin-type steroids following the $\mathrm{D} \rightarrow \mathrm{ABCD}$ approach is reported. A key step is the cobalt-induced cyclization of a cyclopentanoid enediyne, which was prepared via thioalkylation of the zinc enolate of a 2,3-substituted cyclopentanone with $\alpha$-chlorosulfides.
\end{abstract}

Key words: cobalt, cycloaddition, cyclopentanones, steroids, vitamins

Recently, we reported the cobalt-mediated $[2+2+2]$ cycloaddition of 4-hydroxy-substituted enediynes ${ }^{2}$ towards 2-hydroxy-substituted decahydrophenanthrenes. ${ }^{3}$ The hydroxy group in the propargylic position was tolerated under the chosen reaction conditions. Furthermore, it has been demonstrated that this stereogenic center does not have any influence on the formation of the stereogenic centers from the $Z$ double bond, which were transformed to trans-phenanthrenes in a diastereomeric ratio of almost 1:1. These trans-phenanthrenes represent the ABCframework of ergosterin or lumisterin. Consequently, a diastereoselective synthesis of (3S)-hydroxyandrosta-5,7diene-17-ones 1, precursors of vitamin $\mathrm{D}$, was envisioned by following the $\mathrm{D} \rightarrow \mathrm{ABCD}$ approach. Recently, Malacria reported the preparation of 11-aryl-substituted steroids via cobalt(I)-mediated cyclization of allenediynes. ${ }^{4}$

In this convergent synthesis, the racemic ring D (building block 9) and the alkene side chain 7 were connected by a thioalkylation reaction ${ }^{5}$ at a very late stage of the synthesis (Scheme 1). The $\mathrm{PG}^{2}$-protected hydroxy group of cyclopentanone $\mathbf{3}$ was then converted after deprotection, oxidation, and a Corey-Fuchs alkynation to the desired triple bond in 2. After cleavage of the protective group $\mathrm{PG}^{1}$ and Swern oxidation, we introduced the propargylic moiety enantiomerically using a chiral boron-allene complex. ${ }^{6}$ Cobalt-mediated cyclization of enediyne 2 should afford either ergosterin or lumisterin-type steroids. The simultaneous formation of the stereogenic center at C-9 and $\mathrm{C}-10$ of the steroid should be exclusively induced by the trans-configured centers at C-2 and C-3 of the cyclopentanone precursor since the stereogenic center in the sidechain at C-7' does not have any stereochemical influence on the outcome of this cyclization. ${ }^{2}$

For the synthesis of the $\alpha$-chlorosulfides 7 we started from the TBDMS- ${ }^{7}$, TBDPS- ${ }^{8}$ and $\mathrm{Bn}^{9}-\mathrm{O}$-protected pentynols 4 (Scheme 2). After $\mathrm{Cp}_{2} \mathrm{ZrCl}_{2}$-catalyzed carbo-alumination of 4 the corresponding vinyl alanes were treated with $n$-BuLi and ethylene oxide to afford the $E$-alkenols $\mathbf{5}^{2}$ The alcohols $\mathbf{5}$ were mesylated and then transformed into the phenylsulfides 6 by reaction with KSPh in dimethylsulfoxide at room temperature. Finally, chlorination with $\mathrm{N}$-chlorosuccinimide in $\mathrm{CCl}_{4}$ gave the chlorides 7 .

The synthesis of the cyclopentanones 9 was achieved starting from the known racemic 3-hydroxymethyl-2methylcyclopentanone $\mathbf{8}$ by protection of the hydroxy<smiles>CCOC1CC[C@H]2C(=CC=C3CCCC(=O)[C@@]32C)C1</smiles>

1<smiles>CC(=O)OCCC/C(C)=C/CCC1(C)C(=O)CCC1C=O</smiles>

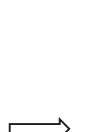<smiles>C#CC[C]([O+])CC/C(C)=C/CC[C@]1(C)C(=O)CC[C@H]1C#C</smiles>

2<smiles>C=C[GeH2]OCCC/C(C)=C/CC(Cl)c1ccccc1</smiles>

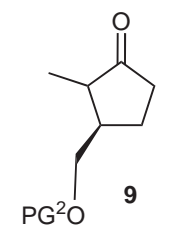

Scheme 1 


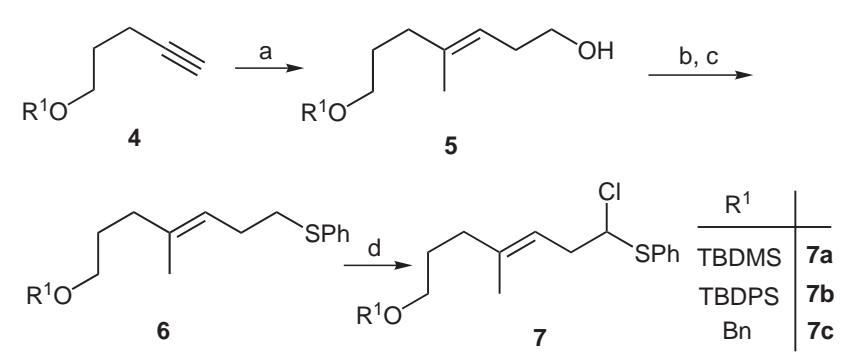

Scheme 2 Reagents and conditions: (a) (i) $\mathrm{AlMe}_{3}$ (3 equiv), $\mathrm{Cp}_{2} \mathrm{ZrCl}_{2}(40 \mathrm{~mol} \%)$, toluene, $0{ }^{\circ} \mathrm{C}, 30 \mathrm{~min}$, then $4,50{ }^{\circ} \mathrm{C}, 76 \mathrm{~h}$; (ii) $n$-BuLi ( 3 equiv), $-65^{\circ} \mathrm{C}$ to $-40{ }^{\circ} \mathrm{C}$, then ethylene oxide ( 3.5 equiv); (b) $\mathrm{Et}_{3} \mathrm{~N}$ (1.5 equiv), $\mathrm{MsCl}$ (1.1 equiv), $\mathrm{CH}_{2} \mathrm{Cl}_{2},-10^{\circ} \mathrm{C}, 15 \mathrm{~min}$; (c) $t$ BuOK (1.2 equiv), PhSH (1.2 equiv), DMSO, r.t., 1 h; (d) NCS (1.3 equiv), $\mathrm{CCl}_{4}$, r.t., 12 h. 7a: $\mathrm{R}^{1}=$ TBDMS $(60 \%$ overall yield $), 7 \mathbf{b}$ : $\mathrm{R}^{1}=\operatorname{TBDPS}\left(55 \%\right.$ overall yield), and $7 \mathrm{c}: \mathrm{R}^{1}=\mathrm{Bn}(44 \%$ overall yield).

group as its silyl ether rac-9a (TBDMSCl and imidazole), as its benzoate ether $r a c-9 b(\mathrm{BzCl}$ and pyridine), or as its benzyl ether $r a c-9 c$ (benzyltrichloroacetimidate) (Scheme 3). ${ }^{10}$

The $\alpha$-thioalkylation of cyclopentanones 9 was achieved by deprotonation of these cyclopentanones with potassium hydride, transmetalation of the generated enolates with $\mathrm{ZnCl}_{2}$ into the zinc enolates and reaction with the $\alpha$-chlorophenyl sulfides 7 . However, only alkylation of the TBDMS-O-protected cyclopentanone 9a with the TBDPS- and Bn-O-protected alkenes $\mathbf{7 b}$ and 7c was successful. While reductive desulfurization of rac-10c with lithium in diethyl amide gave the desired alkene 11 with concomitant cleavage of the benzyl protecting group, the

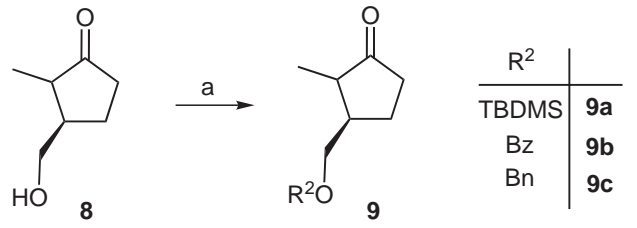

Scheme 3 Reagents and conditions: (a) rac-9a: $\mathrm{R}^{2}=\mathrm{TBDMS}$, TBDMS-Cl (1.2 equiv), imidazole (2.5 equiv), DMF, $0{ }^{\circ} \mathrm{C}$ to r.t., $3 \mathrm{~h}$ (70\%); rac-9b: $\mathrm{R}^{2}=\mathrm{Bz}, \mathrm{BzCl}$ (1.25 equiv), pyridine (1.25 equiv), $\mathrm{CH}_{2} \mathrm{Cl}_{2}$, r.t., $18 \mathrm{~h}(74 \%)$; rac-9c: $\mathrm{R}^{2}=\mathrm{Bn}, \mathrm{BnOC}=\mathrm{NHCCl}_{3}$ (2 equiv), $\mathrm{CH}_{2} \mathrm{Cl}_{2}-\mathrm{THF}(5: 1), 0{ }^{\circ} \mathrm{C}, 2 \mathrm{~h}(60 \%)$.

silyl protected rac-10b decomposed under the same conditions. Protection of $\mathbf{1 1}$ with TBDPSCl and imidazole, resulted in cleavage of the TBDMS group under mild conditions and Swern oxidation of the alcohol obtained provided the aldehyde rac-12. Corey-Fuchs alkynation, ${ }^{11}$ desilylation with $\mathrm{TBAF} \cdot 3 \mathrm{H}_{2} \mathrm{O}$, and oxidation under the same conditions as above gave aldehyde rac-13, which was converted to the enediyne 14 using Yamamoto's chiral allenylboronic ester ${ }^{6}$ and protection of the propargylic alcohol obtained as its MEM ether.

Subsequent $\mathrm{CpCo}(\mathrm{CO})_{2}$-mediated $[2+2+2]$ cycloaddition of the diastereomeric pair 14/14' $(1: 1)$ in refluxing toluene with exposure to visible light followed by oxidative demetallation with $\mathrm{FeCl}_{3}$ afforded the $(3 S)$-hydroxyandrosta-5,7-diene-17-ones $\mathbf{1 5}$ (Scheme 5). ${ }^{12}$ Both the ratio and the absolute configuration of the obtained steroids were determined by comparison of their ${ }^{13} \mathrm{C}$ NMR spectra with the ${ }^{13} \mathrm{C}$ NMR spectrum of an authentic sample of (3 $\left.\beta\right)-3-$ methoxyethoxymethoxyandrosta-5,7-dien-17-one $\quad \mathbf{1 7}^{14}$
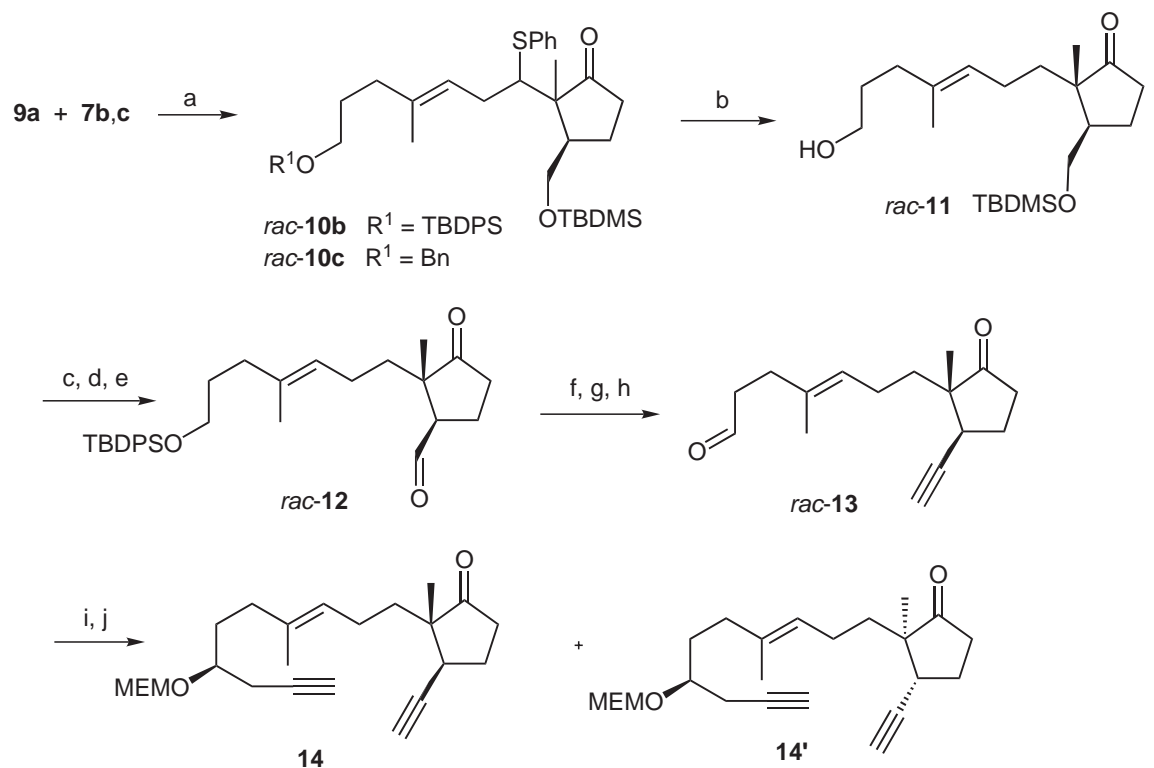

Scheme 4 Reagents and conditions: (a) $\mathrm{KH}$ (1 equiv), THF, r.t., then $\mathrm{ZnCl}_{2}\left(2.5\right.$ equiv), $-15{ }^{\circ} \mathrm{C}$ to $-80{ }^{\circ} \mathrm{C}$, then $7,-80{ }^{\circ} \mathrm{C}$ to r.t., 15 h; $7 \mathbf{b}$ : $\mathrm{R}^{1}=\mathrm{TBDPS}(32 \%, \mathbf{1 0 b}) ; 7 \mathrm{c}: \mathrm{R}^{1}=\mathrm{Bn}(35 \%, 10 \mathrm{c})$; (b) $\mathrm{R}^{1}=\mathrm{Bn}, \mathrm{Li}$ (3 equiv), EtNH $\mathrm{E}_{2},-20{ }^{\circ} \mathrm{C}$ to reflux (68\%); (c) TBDPSCl (1.2 equiv), imidazole (2.5 equiv), DMF, r.t. (94\%); (d) $1 \% \mathrm{HCl}$ in $\mathrm{EtOH}$, r.t., $2 \mathrm{~h}(80 \%)$; (e) $(\mathrm{COCl})_{2}, \mathrm{Et}_{3} \mathrm{~N}, \mathrm{DMSO} \mathrm{CH}_{2} \mathrm{Cl}_{2},-65{ }^{\circ} \mathrm{C}(94 \%)$; (f) (i) $\mathrm{PPh} 3(4$ equiv), $\mathrm{CBr}_{4}$ (2 equiv), $\mathrm{CH}_{2} \mathrm{Cl}_{2}, 0{ }^{\circ} \mathrm{C}, 30 \mathrm{~min}$, then 12, $30 \mathrm{~min}(76 \%)$; (ii) $t$-BuLi (3 equiv), THF, $-80{ }^{\circ} \mathrm{C}, 30 \mathrm{~min}(78 \%)$; (g) $\mathrm{TBAF} \cdot 3 \mathrm{H}_{2} \mathrm{O}(1.2 \mathrm{equiv})$, THF, r.t., $4 \mathrm{~h}(90 \%)$; (h) $(\mathrm{COCl})_{2}, \mathrm{Et}_{3} \mathrm{~N}$, DMSO, $\mathrm{CH}_{2} \mathrm{Cl}_{2},-65{ }^{\circ} \mathrm{C}(78 \%)$; (i) $\mathrm{CH}_{2}=\mathrm{C}=\mathrm{CHB}(\mathrm{OH})_{2}$ (1 equiv), D-(-)-diisopropyl tartrate (2 equiv), toluene, $-80{ }^{\circ} \mathrm{C}$, then $13,24 \mathrm{~h}(78 \%)$; (j) $i$ - $\mathrm{Pr}_{2} \mathrm{NEt}$ (1.5 equiv), $\mathrm{CH}_{3} \mathrm{OCH}_{2} \mathrm{CH}_{2} \mathrm{OCH}_{2} \mathrm{Cl}\left(1.5\right.$ equiv), $\mathrm{CH}_{2} \mathrm{Cl}_{2}, 0{ }^{\circ} \mathrm{C}$ to r.t., $18 \mathrm{~h}(88 \%)$. 
This was synthesized starting from commercially available $^{13}(3 \beta)$-3-androsta-5-en-17-one 16 by employing the phenylsulfoxide method of Confalone and co-workers (Scheme 6). ${ }^{14}$

Starting from a 1:1 mixture of $\mathbf{1 4}$ and $\mathbf{1 4}^{\prime}$ the formation of the stereogenic centers C-9 and C-10 should be controlled only by the cyclopentanoid moiety. Consequently, the diastereomeric pairs $\mathbf{1 5 a} / \mathbf{1 5}^{\prime} \mathbf{a}$ and $\mathbf{1 5} \mathbf{b} / \mathbf{1 5}^{\prime} \mathbf{b}$ must be obtained each in a 1:1 ratio. The lumisterin and ergosterin precursors ratio of $\mathbf{1 5 a} / \mathbf{1 5 b}$ was found to be $7: 1$ after the ${ }^{13} \mathrm{C}$ NMR data of $\mathbf{1 5 b}$ were determined, which coincided with those of 17, prepared from 16 (Scheme 6). Table 1 shows selected data and the ratio of the prepared steroids.
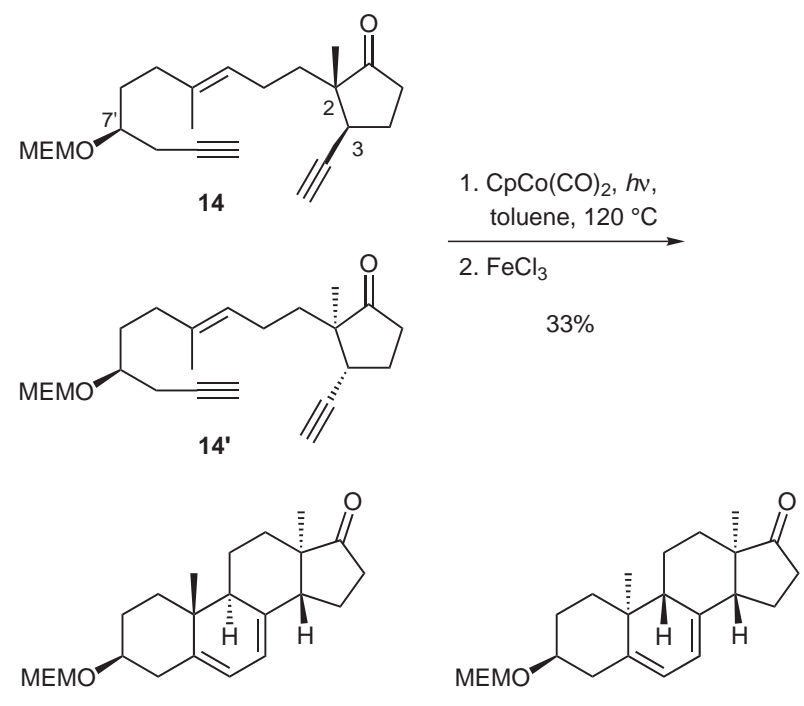

15 'a

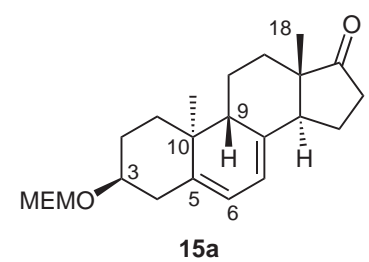

lumisterin precursor

7

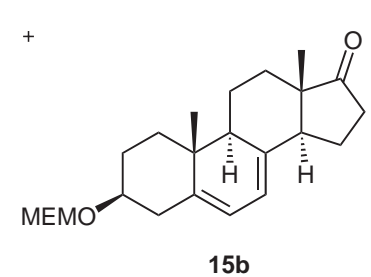

ergosterin precursor

1

Scheme 5

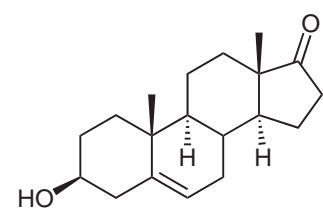

16

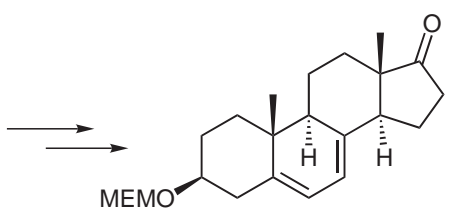

17
Scheme 6

In summary, the formation of the tetracyclic core $\mathbf{1}$ is reported via an intramolecular cobalt-mediated $[2+2+2]$ cycloaddition of an enediyne, which has been synthesized starting from a substituted thiochloride and a 2,3-disubstituted cyclopentanone. Since several chiral syntheses of
Table 1 Selected ${ }^{13} \mathrm{C}$ NMR data

\begin{tabular}{lccccc}
\hline Steroid $^{\mathrm{a}}$ & \multicolumn{1}{c}{$\mathbf{1 5 a}$} & \multicolumn{1}{c}{$\mathbf{1 5}^{\prime} \mathbf{a}$} & \multicolumn{1}{c}{$\mathbf{1 5}^{\prime} \mathbf{b}$} & \multicolumn{1}{c}{$\mathbf{1 5 b}$} & \multicolumn{1}{c}{$\mathbf{1 7}^{\mathrm{b}}$} \\
\hline C-3 & 70.74 & 75.81 & 71.00 & 75.31 & 75.32 \\
C-5 & 140.82 & 142.15 & 139.16 & 141.16 & 141.14 \\
C-6 & 120.00 & 119.66 & 119.54 & 119.21 & 119.22 \\
C-18 & 13.66 & 13.81 & 13.95 & 13.51 & 13.50 \\
Ratio & 7 & 7 & 1 & 1 & - \\
\hline
\end{tabular}

${ }^{a}$ Chemical shift in ppm.

${ }^{\mathrm{b}}$ Prepared from 16 in enantiomerically and diastereomerically pure form.

substituted cyclopentanones and cyclopentanes are wellknown, ${ }^{1 \mathrm{a}}$ the synthesis of the steroid skeleton described herein offers a new convergent approach to vitamin D compounds (deltanoids) following the construction principle $\mathrm{D} \rightarrow \mathrm{ABCD}$. Extension of this strategy to the synthesis of substituted steroids (provitamin analogues), which can been transformed directly, after photolysis and thermal isomerization, to related vitamin D is under investigation.

\section{Acknowledgment}

The authors are grateful to the Fonds der Chemischen Industrie for financial support and the Wacker Chemie GmbH for valuable starting materials. N.R. thanks the Cusanus Werk - Bischöfliche Hochbegabtenförderung for a doctoral fellowship.

\section{References and Notes}

(1) (a) Stereoselective Synthesis of Steroids and Related Compounds, VIII. For part VII, see: Groth, U.; Halfbrodt, W.; Kalogerakis, A.; Köhler, T.; Kreye, P. Synlett 2004, 291. (b) Transition Metal Catalyzed Reactions in Organic Synthesis, XI. For part X, see: Groth, U.; Huhn, T.; Kesenheimer, C.; Kalogerakis, A. Synlett 2005, 1758.

(2) Applications to natural products synthesis: (a) Johnson, E. P.; Vollhardt, K. P. C. J. Am. Chem. Soc. 1991, 113, 381. (b) Germanas, J.; Aubert, C.; Vollhardt, K. P. C. J. Am. Chem. Soc. 1991, 113, 4006. (c) Pérez, D.; Siesel, B. A.; Malaska, M. J.; David, E.; Vollhardt, K. P. C. Synlett 2000, 306. (d) Eichberg, M. J.; Dorta, R. L.; Lamottke, K.; Vollhardt, K. P. C. Org. Lett. 2000, 2, 2479. (e) Eichberg, M. J.; Dorta, R. L.; Grotjahn, D. B.; Lamottke, K.; Schmidt, M.; Vollhardt, K. P. C. J. Am. Chem. Soc. 2001, 123, 9324. For the synthesis of the taxoid core, see also:

(f) Phansavath, P.; Aubert, C.; Malacria, M. Tetrahedron Lett. 1998, 39, 1561. (g) Petit, M.; Chouraqui, G.; Phansavath, P.; Aubert, C.; Malacria, M. Org. Lett. 2002, 4 , 1027.

(3) Groth, U.; Richter, N.; Kalogerakis, A. Eur. J. Org. Chem. 2003, 4634.

(4) (a) Wiechert, R. Angew. Chem., Int. Ed. Engl. 1970, 9, 321; Angew. Chem. 1970, 82, 331. (b) Wiechert, R. Angew. Chem., Int. Ed. Engl. 1970, 16, 506; Angew. Chem. 1977, 89, 513. (c) Quinkert, G.; Stark, H. Angew. Chem., Int. Ed. Engl. 1983, 22, 637; Angew. Chem. 1983, 95, 651. (d) Steglich, W.; Fugmann, B.; Lang-Fugmann, S. RÖMPP Natural 
Products; Thieme: Stuttgart, 2000, 608. (e) Krause, S.; Schmalz, H.-G. In Organic Synthesis Highlights, IV; WileyVCH: Weinheim, 2000, 212. (f) Posner, G. H.; Kahraman, M. Eur. J. Org. Chem. 2003, 3889. (g) Habermehl, G.; Hammann, P. E.; Krebs, H. C. Naturstoffchemie; Springer: Berlin, 2002, 49. (h) Recently, a new method for the construction of steroids was reported: Sünnemann, H. W.; de Meijere, A. Angew. Chem. 2004, 116, 913; Angew. Chem. Int. $E d$. 2004, 43, 895. (i) For the use of the $\mathrm{D} \rightarrow \mathrm{ABCD}$ approach in the synthesis of steroids see also: Vollhardt, K. P. C. Pure Appl. Chem. 1985, 57, 1819. (j) Petit, M.; Aubert, C.; Malacria, M. Org. Lett. 2004, 6, 3937.

(5) Groth, U.; Huhn, T.; Richter, N. Liebigs Ann. Chem. 1993, 49.

(6) (a) Haruta, R.; Ishiguro, M.; Ikeda, N.; Yamamoto, H. J. Am. Chem. Soc. 1982, 104, 7667. (b) Ikeda, N.; Isao, A.; Yamamoto, H. J. Am. Chem. Soc. 1986, 108, 483.

(7) Pereira, R.; Iglesias, B.; Lera, A. R. Tetrahedron 2001, 57, 7871.

(8) Baldwin, J. E.; Romeril, S. P.; Lee, V.; Claridge, T. D. W. Org. Lett. 2001, 3, 1145.

(9) Franck, X.; Araujo, M. E. V.; Julian, J.-C.; Hocquemiller, R.; Figadère, B. Tetrahedron Lett. 2001, 42, 2801.

(10) Eckenberg, P.; Groth, U.; Huhn, T.; Richter, N.; Schmeck, C. Tetrahedron 1993, 49, 1619.

(11) Corey, E. J.; Fuchs, P. L. Tetrahedron Lett. 1972, 36, 3769.

(12) Cobalt-mediated [2+2+2] cycloaddition: A solution of enediyne $14(200 \mathrm{mg}, 0.54 \mathrm{mmol})$ in toluene $(80 \mathrm{~mL})$ was cooled to $-70{ }^{\circ} \mathrm{C}$ and the apparatus was evacuated for $3 \mathrm{~min}$ ( 0.5 Torr). The flask was allowed to warm to r.t. and the apparatus was filled with argon. The solution of enediyne in toluene was cooled to $-70^{\circ} \mathrm{C}$ and the above procedure was repeated twice. $\mathrm{CpCo}(\mathrm{CO})_{2}(117 \mathrm{mg}, 0.65 \mathrm{mmol})$ was added and the reaction mixture was refluxed under radiation with visible light until no starting material could be detected by TLC analysis. The reaction mixture was cooled to r.t. and volatile components were removed in vacuo $\left(20^{\circ} \mathrm{C} / 0.1\right.$
Torr). The residue was dissolved in degassed $\mathrm{Et}_{2} \mathrm{O}$-pentane $(1: 4,10 \mathrm{~mL})$ and filtered through celite under an argon atmosphere. $\mathrm{FeCl}_{3} \cdot \mathrm{H}_{2} \mathrm{O}(0.49 \mathrm{~g}, 1.8 \mathrm{mmol})$ was dissolved in $\mathrm{MeCN}(20 \mathrm{~mL})$, pentane $(20 \mathrm{~mL})$ was added and the mixture cooled to $-20{ }^{\circ} \mathrm{C}$. At this temperature the filtrate was added under stirring, and stirring was continued for $30 \mathrm{~min}$. The reaction mixture was cooled to $-60^{\circ} \mathrm{C}$ and the pentane layer was removed from the frozen $\mathrm{MeCN}$ layer. The $\mathrm{MeCN}$ layer was allowed to warm to $-20^{\circ} \mathrm{C}$, pentane $(15 \mathrm{~mL})$ was added, and the above procedure was repeated four times. The pentane layers were combined, the solvent was removed in vacuo $\left(30^{\circ} \mathrm{C} / 18\right.$ Torr $)$, and the residue purified by chromatography on silica gel $\left(\mathrm{Et}_{2} \mathrm{O}\right.$-pentane, $\left.1: 1\right)$ to afford steroids 15 (66.65 mg, $0.18 \mathrm{mmol}, 33 \%$ ).

Compound 15a/15'a (signals of the major diastereomeric pair): $R_{f}=0.27\left(\mathrm{Et}_{2} \mathrm{O}-\mathrm{PE}, 1: 1\right) .{ }^{1} \mathrm{H} \mathrm{NMR}(250 \mathrm{MHz}$, $\left.\mathrm{CDCl}_{3}\right): \delta=0.76$ and $0.84\left(2 \mathrm{~s}, 6 \mathrm{H}, 2 \times \mathrm{CH}_{3}\right), 1.20-2.80(\mathrm{~m}$, $\left.16 \mathrm{H}, \mathrm{CH}_{2}, \mathrm{CH}\right), 3.40\left(\mathrm{~s}, 3 \mathrm{H}, \mathrm{OCH}_{3}\right), 3.50-3.64$ and 3.66$3.79\left(2 \times \mathrm{m}, 5 \mathrm{H}, \mathrm{OCH}_{2} \mathrm{CH}_{2} \mathrm{O}, \mathrm{OCH}\right), 4.78(\mathrm{dd}, J=6 \mathrm{~Hz}$, $\left.6 \mathrm{~Hz}, 2 \mathrm{H}, \mathrm{OCH}_{2} \mathrm{O}\right), 5.47-5.68(\mathrm{~m}, 2 \mathrm{H}, \mathrm{C}=\mathrm{CHC}=\mathrm{CH})$.

${ }^{13} \mathrm{C}$ NMR $\left(50.3 \mathrm{MHz}, \mathrm{CDCl}_{3}\right): \delta=13.66$ and $13.81(\mathrm{C}-18)$, $18.05,18.38,20.20,20.23,26.17,28.80,29.06,33.96$, $35.78,35.85,35.93,36.12,37.08,38.03$, and 38.28 (C-1, C2, C-4, C-10, C-11, C-12, C-15, C-16), 20.30 (C-19), 46.27 and 46.58 (C-9), 46.77 (C-13), 59.04 (C-23), 66.78 and 71.79 (C-21, C-22), 70.74 and 75.81 (C-3), 93.35 and 93.73 (C-20), 116.50, 116.57, 119.66 and 119.99 (C-6, C-7), 137.46, 137.94, 140.82 and $142.15(\mathrm{C}-5, \mathrm{C}-8), 220.97$ and $221.15(\mathrm{C}-17)$. MS $(70 \mathrm{eV}): \mathrm{m} / \mathrm{z}(\%)=374(2)\left[\mathrm{M}^{+}\right], 268$ (100) $\left[\mathrm{M}-\mathrm{C}_{4} \mathrm{H}_{10} \mathrm{O}_{3}\right]^{+}, 89(35)\left[\mathrm{C}_{4} \mathrm{H}_{10} \mathrm{O}_{3}^{+}\right], 59$ (60) $\left[\mathrm{C}_{3} \mathrm{H}_{7} \mathrm{O}^{+}\right.$]. HRMS: $m / z$ calcd $\mathrm{C}_{23} \mathrm{H}_{34} \mathrm{O}_{4}$ for 374.2457 ; found: 374. 2459.

(13) Purchased from Aldrich.

(14) (a) Confalone, P. N.; Kulesha, I. D.; Uskoković, M. R. J. Org. Chem. 1981, 46, 1030. (b) Okabe, M.; Sun, R.-C.; Scalone, M.; Jibilian, C. H.; Hutchings, S. D. J. Org. Chem. 1995, 60, 767. 